\title{
Assessment of enamel-dentin caries lesions detection using bitewing PSP digital images
}

\author{
Marianna Guanaes Gomes TORRES ${ }^{1}$, Aline da Silva SANTOS², Frederico Sampaio NEVES ${ }^{3}$, Marcel Lautenschlager \\ ARRIAGA ${ }^{4}$, Paulo Sérgio Flores CAMPOS $^{5}$, lêda CRUSOÉ-REBELLO ${ }^{5}$
}

1- DDS, MSc, PhD student, Department of Oral Radiology, School of Dentistry, Federal University of Bahia, Salvador, BA, Brazil.
2- DDS, Department of Oral Radiology, School of Dentistry, Federal University of Bahia, Salvador, BA, Brazil.
3- DDS, MSc, PhD student, Department of Oral Diagnosis, Piracicaba Dental School, State University of Campinas, Piracicaba, SP, Brazil.
4- DDS, MSc, PhD, Department of Public Health, School of Dentistry, Federal University of Bahia, Salvador, BA, Brazil.
5- DDS, MSc, PhD, Department of Oral Radiology, School of Dentistry, Federal University of Bahia, Salvador, BA, Brazil.

Corresponding address: lêda Crusoé-Rebello - Rua Marechal Floriano, n 448 - Canela - Salvador, BA - Brasil - $40110-010$ - Phone: +55 (71) 33360049 - e-mail: ieda@radiologia.odo.br

Received: July 29, 2009 - Modification: May 12, 2010 - Accepted: October 26, 2010

\section{ABSTRACT}

\begin{abstract}
bjectives: The aim of this study was to evaluate the detection of enamel-dentin occlusal caries using photostimulable phosphor plates. Material and Methods: The ability to detect enamel-dentin occlusal caries in 607 premolars and molars from 47 patients between 10 and 18 years old, referred to the School of Dentistry of the Federal University of Bahia, Brazil, was evaluated based on clinical and radiographic examinations, using the criteria proposed in a previous study. A total of 156 bitewing digital images were obtained using Digora $\mathbb{R}$ (Soredex Medical Systems, Helsinki, Finland) phosphor plates. The plates were scanned and the images were captured and displayed on a computer screen. Image evaluation was done using Digora ${ }^{\circledR}$ for Windows 2.1 software, Soredex $®$. The radiologists were allowed to use enhancement tools to obtain better visibility during scoring of the teeth based on the radiographic criteria proposed in a previous study. Descriptive analysis and chi-squared proportion tests were done at 5\% significance level. Results: The results of clinical examination showed a higher prevalence of teeth with a straight dark line or demineralization of the occlusal fissure (score 1) and a lower prevalence of sealed teeth (score 5). In the bitewing digital images, 47 teeth presented visible radiolucency, circumscribed, in dentin under occlusal enamel (enamel-dentin caries lesions). Conclusions: Correlating the clinical and radiographic findings, it was found that in the majority of teeth diagnosed by radiographic images as having enamel-dentin caries, no caries could be detected by clinical examination.
\end{abstract}

Key words: Dental caries. Bitewing radiographs. Digital radiography. Photostimulable phosphor.

\section{INTRODUCTION}

The detection of caries lesions is still a matter of investigation in Dentistry. Epidemiologic studies have shown that non-cavitated lesions are more prevalent than cavitated lesions ${ }^{3,8}$. Extensive lesions can develop in dentin beneath an apparently sound enamel crown, or superficial occlusal lesion, which may ultimately undermine the enamel ${ }^{7}$.

Enamel-dentin caries, also known as hidden caries, is a phenomenon that leads to formation of highly mineralized, strengthened enamel surfaces, under which the loss of mineral may progress gradually and the carious lesion might extend into dentin without a clinically visible crack at the enamel surface. There is no consensus on the cause of enamel-dentin caries. It has been suggested that, despite the indubitable benefits, the high remineralization capacity of fluoride might mask dentin caries, mainly for those who have lifelong exposure to water fluoridation. An alternative hypothesis is that the phenomenon occurs as a result of interactions between enamel and dentin $7,13,14$.

When a small, localized, developing enamel lesion crosses the dentinoenamel junction into the 
dentin, relatively high concentrations of dentin dissolution products could be sufficient to prevent or retard dissolution of enamel but insufficient to confer the same degree of protection on the more soluble dentin. This would leave the dentin lesion to progress undetected beneath an apparently intact or superficially demineralized enamel crown. The potential also exists for remineralization of an occlusal enamel lesion to occur while the dentin continues to dissolve, which could mask the enamel demineralization and further increase the difficulty of detecting the enamel-dentin caries ${ }^{7}$.

It is not known whether hidden caries exists as a distinct entity and it has been asserted that to use the term simply implies an insufficient clinical examination. However, concern has been expressed at the difficult of detecting occlusal caries lesions under apparently sound enamel7,17,18. Thus, the detection of enamel-dentin caries, or hidden caries, is difficult, and the association of different diagnosis methods is fundamental to determine the presence of these lesions. The radiographic exam, used as a complement of the clinical visual exam, is a disposable tool for dental researchers and professionals $\mathrm{s}^{4,5,20}$.

Digital image systems demonstrate diagnostic accuracy comparable to conventional radiography4-6,11,15,22. Digital systems present a significant reduction in exposure to radiation of $50-90 \%$. Digital receptors are more sensitive to radiation than film, require less exposure to radiation, and chemical processing are not needed ${ }^{5,21}$.

Digora ${ }^{\circledR}$ (Soredex Medical Systems, Helsinki, Finland) is one of the several digital systems that use an optical plate, composed of photofluorescent particles that are sensitive to $x$-rays, forming a latent image. The optic plate is scanned on a Digora ${ }^{\circledR}$ optic scanner, and the final image is displayed on a computer screen. The final image can be enhanced using the system's software enhancement tools ${ }^{10,21}$.

The present study evaluated the detection of enamel-dentin occlusal caries using photostimulable phosphor plates. The specific aims were: to evaluate the frequency of enamel-dentin occlusal caries in relation to gender and age; to compare the occurrence of enamel-dentin occlusal caries in different tooth groups; to compare detection of enamel-dentin occlusal caries based on digital images with detection based on clinical findings using the criteria proposed by Weerheijm, Gruythuysen and Van Amerongen ${ }^{19}$ (1992).

\section{MATERIAL AND METHODS}

In agreement with the Departments of Cariology, Pediatric Dentistry, and Dentistry II of the School of Dentistry of the Federal University of Bahia (FOUFBA), new patients aged between 10 and 18 years, which is the age range with the highest prevalence of enamel-dentin caries $^{18}$, were evaluated clinically. The purpose of the research was explained and patient informed assent forms for minors and patient informed consent forms for adults and parents/guardians were signed. This study was approved by the FOUFBA's Research Ethics Committee (Protocol number 0006.0.368.000-07).

Before the examination sessions, verbal and practical instructions and calibration tests were performed. For the calibration tests, the occlusal surfaces in 10 patients (maxillary and mandibular arches) were evaluated based on the criteria proposed by Weerheijm, Gruythuysen and Van Amerongen ${ }^{19}$ (1992) (Figure 1), by two researchers, under the same conditions, and with inter-examiner agreement of 0.98 and kappa value of 0.92 .

After supervised toothbrushing, the teenagers were examined in supine position, under a standard dental operating light, and with compressed air to dry the surfaces to be evaluated. For the visual examination, a plain mouth mirror was necessary to hold back the soft tissue and permit better visualization of the area. The visual examination was completed using a no. 5 probe to remove any residual dental plaque by applying soft pressure. The occlusal surfaces of permanent premolars and molars were clinically evaluated, based on the criteria of Weerheijm, Gruythuysen and Van Amerongen $^{19}$ (1992). Scores of 1 and 2 represent lesions with depth limited to the enamel and no signs of caries in dentin. The occlusal surfaces were divided into the following groups: sound, a combination of criteria $0,1,2$ and 5; completely sound, exclusively criteria 0 ; and presence of disease, criteria 3 and 4.

\begin{tabular}{|l|l|}
\hline 0 & Sound (absence of demineralization or color change) \\
\hline 1 & Presence of a straight dark line or demineralization on the occlusal fissure \\
\hline 2 & Presence of a wide dark line, or a straight and dark line, combined with fissure demineralization \\
\hline 3 & Dentine lesion \\
\hline 4 & Restored \\
\hline 5 & Sealed \\
\hline
\end{tabular}

Figure 1- Weerheijm, Gruythuysen and Van Amerongen ${ }^{19}$ (1992) criteria for clinical examination 
The bitewing radiographic exam was part of the treatment protocol in this study for patients without dentin lesions; for teeth with dentin lesion with possible pulp lesion, periapical radiographs were used as a complementary diagnostic method.

Using the Digora ${ }^{\circledR}$ digital system, phosphor plates and radiographic bitewing Han-Shin film holders (JON, São Paulo, SP, Brazil), all patients clinically evaluated were radiographed using a Timex 70 C machine (Gnatus, Ribeirão Preto, SP, Brazil), with fixed parameters: $70 \mathrm{kVp}, 3 \mathrm{~mA}, 0.3$ seconds. Bitewing views of premolar and molar areas were obtained.

The images were evaluated by two experienced radiologists, at different times, in a dimly lit room, with a cardboard simulating a black mask attached to the monitor, so that the image seen by the observer corresponded to the real image size, and shielding it from the light emitted by the screen. Image evaluation was done using Digora ${ }^{\circledR}$ for Windows 2.1 software, Soredex ${ }^{\circledR}$. The radiologists were allowed to use zoom and other enhancement tools for better visualization during the scoring of the teeth based on the aforementioned criteria ${ }^{19}$ (Figure 2). Figure 3 shows the radiographic aspects of the occlusal surfaces according to the criteria adopted in the study ${ }^{19}$. In case of disagreements, both observers evaluated the images again until they came to a consensus.

Technical files were created based on the criteria of Weerheijm, Gruythuysen and Van Amerongen ${ }^{19}$ (1992) to archive the data from the clinical and radiographic examinations of each patient. The data were correlated. Descriptive analysis and chisquared proportion tests were done; a $p$ value of $\leq 0.05$ was considered significant.

At a later moment, the teeth with presence of visible radiolucency, circumscribed, in dentin under occlusal enamel (enamel-dentin caries lesions) were opened and the accuracy of the method was evaluated.

\section{RESULTS}

Six hundred and seven teeth of 47 patients were evaluated (17 males and 30 females). The mean age was $12.78 \pm 2.50$ years. Of the 607 clinically evaluated teeth, 121 were second molars, 179 were first molars, 145 were second premolars and 162 were first premolars (Figure 4). The teeth were distributed based on the criteria adopted in the study $^{19}$ (Figure 5).

Teeth with dark stained straight lines or demineralization on the occlusal fissure (score 1) were the most prevalent (229-37.73\%), followed by sound teeth (scored as $0,224-36.90 \%$ ). The least prevalent pattern was score 5 at $2.14 \%$ of the total sample.

The radiographic evaluation was done by two experienced dental radiologists, who obtained a high inter-examiner reproducibility value (kappa value 0.89 ). The results for the radiographic evaluation are shown in Figure 6. The distribution of the 47 teeth with enamel-dentin caries based on Weerheijm, Gruythuysen and Van Amerongen ${ }^{19}$ (1992) clinical criteria is shown on Table 1.

Of the 47 patients examined, 24 did not present enamel-dentin occlusal caries, and 23 had enameldentin occlusal caries. The distribution of patients by gender with and without enamel-dentin caries is shown on Table 2 . The chi-squared test was used to evaluate the difference between the prevalence of enamel-dentin caries lesions for females and males, and there was no significant difference between the two groups $(p=0.9672)$ (Table 2$)$.

The presence or absence of enamel-dentin caries was also evaluated for different age groups (10-12 years, $13-15$ years and $16-18$ years). There was no

\begin{tabular}{|l|l|}
\hline 0 & Absence of any visible radiolucency in dentine under occlusal enamel \\
\hline 3 & $\begin{array}{l}\text { Presence of visible radiolucency, circumscribed, in dentine under occlusal enamel-enamel-dentine caries } \\
\text { lesions (only high quality pattern radiographic images) }\end{array}$ \\
\hline 4 & Radiopaque image suggesting restoration \\
\hline 6 & Impossible to judge and density measurement and histogram tools may be applied \\
\hline
\end{tabular}

Figure 2- Weerheijm, Gruythuysen and Van Amerongen ${ }^{19}$ (1992) criteria for radiographic examinations

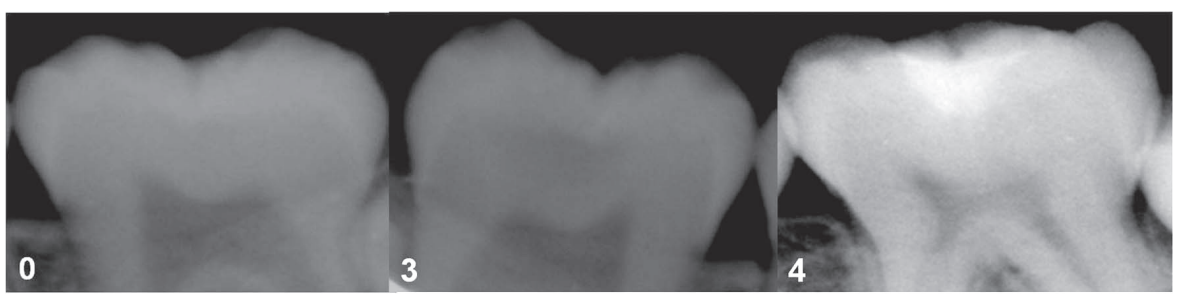

Figure 3- Radiographic aspects of the occlusal surfaces according to Weerheijm, Gruythuysen and Van Amerongen ${ }^{19}$ (1992) criteria 
statistically significant difference $(p=0.87)$ for the prevalence of enamel-dentin lesions among these age groups.

When evaluating different dental groups for the presence of enamel-dentin caries, 14.29\% (17 teeth) of the second molars presented enamel-



Figure 4- Distribution of evaluated teeth based on tooth groups ( $1^{\text {st }}$ premolar, $2^{\text {nd }}$ premolar, $1^{\text {st }}$ molar and $2^{\text {nd }}$ molar $)$ dentin caries, $15.12 \%$ ( 26 teeth) of the first molars, $1.47 \%$ ( 2 teeth) of the second premolars and $1.51 \%$ ( 2 teeth) of the first premolars. This shows that enamel-dentin caries was more frequently found in molars (Figure 7 ).

Table 3 shows the frequency of different clinical aspects (criteria 0, 1, 2, 3, 4 and 5) in teeth with enamel-dentin caries based on tooth group (second

Table 1- Distribution of teeth with enamel-dentin caries based on Weerheijm, Gruythuysen and Van Amerongen ${ }^{19}$ (1992) clinical criteria

\begin{tabular}{cc}
\hline Criteria & Enamel-dentine caries lesions (\%) \\
\hline 0 & $7(14.89)$ \\
1 & $10(21.28)$ \\
2 & $24(51.06)$ \\
3 & $5(10.64)$ \\
4 & 0 \\
5 & $1(2.13)$ \\
\hline
\end{tabular}

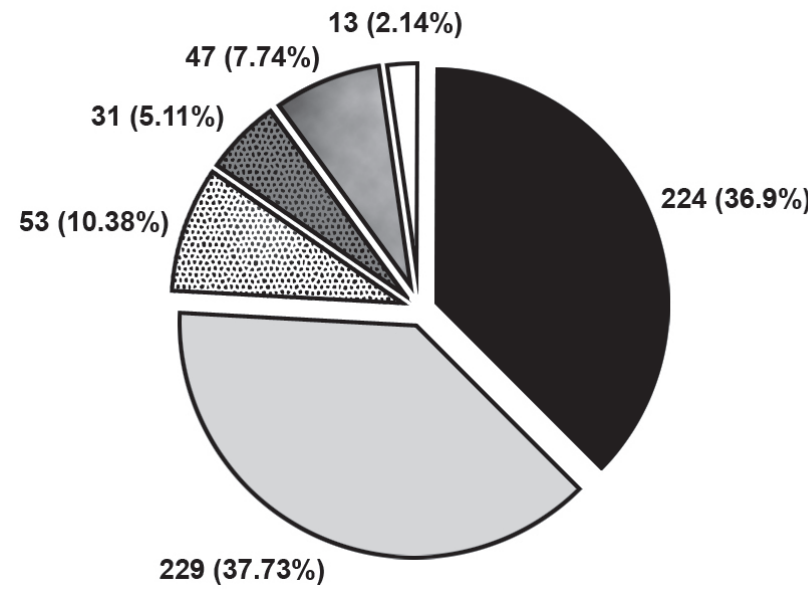

$\square 0$ - no color change of decalcification
$\square 1$ - straight, dark line/decalcification
畻 2 - wide dark line/straight, dark line + decalcification
圈 3 - dentrine lesion
$\square 4$ - restored
$\square 5$ - sealed

Figure 5- Distribution of Weerheijm, Gruythuysen and Van Amerongen ${ }^{19}$ (1992) clinical criteria on the evaluated teeth

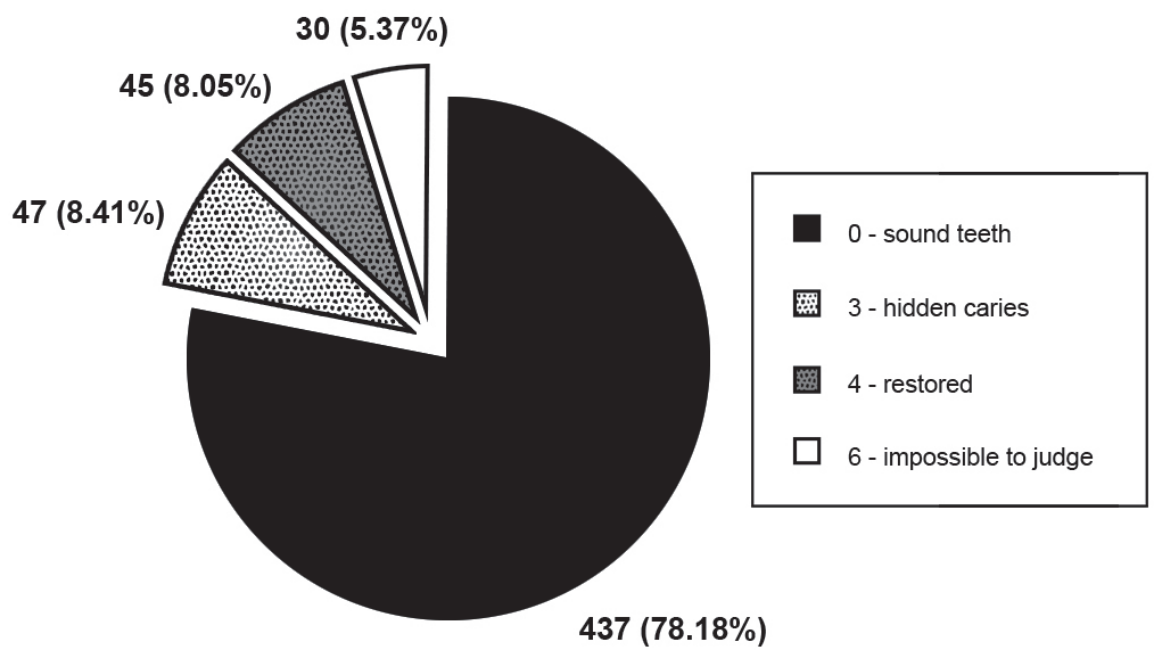

Figure 6- Distribution of Weerheijm, Gruythuysen and Van Amerongen ${ }^{19}$ (1992) radiographic criteria on the evaluated teeth 
molars, first molars, second premolars or first premolars). First molars and second molars showed a statistically significant difference among the clinical diagnosis criteria, with a predominance of criterion 2 (a wide dark stained line or demineralization in fissure) in a larger number of teeth $(p=0.05)$.

When evaluating the distribution of enameldentin lesions on maxillary and mandibular teeth, it was found that maxillary premolars and molars were less affected by enamel-dentin caries (16 teeth) than the mandibular premolars and molars (31 teeth), although that difference was not statistically significant $(p=0.075)$ (Table 4$)$.

Of the 47 teeth diagnosed by radiographic examination as having enamel-dentin caries, 9 were

Table 2- Distribution of patients by gender with and without enamel-dentin caries $(p=0.9672)$

\begin{tabular}{cccc}
\hline $\begin{array}{c}\text { Enamel- } \\
\text { dentine caries }\end{array}$ & \multicolumn{2}{c}{ Gender } & Total (\%) \\
& Male (\%) & Female (\%) \\
\hline Absence & $9(37.50)$ & $15(62.50)$ & $24(51.06)$ \\
Presence & $8(34.78)$ & $15(65.21)$ & $23(48.94)$ \\
Total & $17(36.17)$ & $30(63.83)$ & $47(100.00)$ \\
\hline
\end{tabular}

opened for treatment and all of them presented dentin caries lesions. These teeth were restored with composite resin and one of them required endodontic treatment due to pulp infection caused by an extensive caries lesion. The remaining teeth diagnosed as having enamel-dentin caries were treated with non-invasive procedures (fluoride therapy and/or sealant placement) and monitoring, based on a multidisciplinary decision.

The teeth classified according to the criteria of Weerheijm, Gruythuysen and Van Amerongen ${ }^{19}$ (1992) as score 6 on radiographic images (Figure 3 ) had the clinical option of monitoring the lesion.

\section{DISCUSSION}

The total number of teeth evaluated by radiographic examination (559) did not correspond to the total number of teeth evaluated clinically (607), so there was a difference of 48 teeth, due to incomplete imaging of some teeth in the radiographs.

Based on tooth eruption chronology, $1^{\text {st }}$ molars erupt earlier than $2^{\text {nd }}$ molars and then $1^{\text {st }}$ and $2^{\text {nd }}$ premolars. As their contact with the oral cavity is longer than the other posterior teeth, they are more susceptible to dental caries and cavitated lesions,



Figure 7- Distribution of Weerheijm, Gruythuysen and Van Amerongen ${ }^{19}$ (1992) radiographic criteria on the different tooth groups $(\mathrm{M}=$ molar; $\mathrm{PM}=$ premolar $)$

Table 3- Frequency of different clinical aspects of teeth with enamel-dentin caries related to tooth group $(p=0.5)$

\begin{tabular}{|c|c|c|c|c|c|}
\hline \multirow[t]{2}{*}{ Clinical criterion } & \multicolumn{4}{|c|}{ Enamel-dentine caries } & \multirow[t]{2}{*}{ Total (\%) } \\
\hline & $2^{\text {nd }} M(\%)$ & $1^{\text {st }} M(\%)$ & $2^{\text {nd }} P M(\%)$ & $1^{\text {st }} \mathrm{PM}(\%)$ & \\
\hline 0 & $5(29.41)$ & $1(3.85)$ & 0 & $1(50.00)$ & 7 (14.89) \\
\hline 1 & $1(5.88)$ & $7(26.92)$ & $1(50.00)$ & $1(50.00)$ & $10(21.28)$ \\
\hline 2 & $8(47.06)$ & $16(61.54)$ & 0 & 0 & $24(51.06)$ \\
\hline 3 & $3(17.65)$ & $1(3.85)$ & $1(50.00)$ & 0 & $5(10.64)$ \\
\hline 4 & 0 & 0 & 0 & 0 & 0 \\
\hline 5 & 0 & $1(3.85)$ & 0 & 0 & $1(2.13)$ \\
\hline Total & $17(36.17)$ & $26(55.32)$ & $2(4.25)$ & $2(4.25)$ & $47(100)$ \\
\hline
\end{tabular}

$(\mathrm{M}=$ molar; $\mathrm{PM}=$ premolar $)$ 
Table 4- Distribution of enamel-dentin caries on maxillary and mandibular premolars and molars $(p=0.075)$

\begin{tabular}{cccc}
\hline $\begin{array}{c}\text { Enamel- } \\
\text { dentine caries }\end{array}$ & Arch & Total (\%) \\
& Upper (\%) & Lower (\%) \\
\hline Absence & $270(52.73)$ & $242(47.27)$ & $512(91.59)$ \\
Presence & $15(31.91)$ & $32(68.09)$ & $47(8.41)$ \\
Total & $285(50.98)$ & $274(49.02)$ & $559(100.00)$ \\
\hline
\end{tabular}

and are also frequently restored ${ }^{2}$. That can explain the occurrence of more sealed surfaces on $1^{\text {st }}$ molars (11 $1^{\text {st }}$ molars of 13 sealed teeth) and the occurrence of restorations in this same group of teeth (27 $1^{\text {st }}$ molars of 47 restored teeth); premolars presented completely sound occlusal surfaces (score 0 ) in a high number of teeth compared with molars (155 premolars and 69 molars).

In the present study, 32 teeth presented cavities during clinical examination, and 47 teeth presented enamel-dentin occlusal caries, demonstrating a higher occurrence of non-cavitated lesions than cavitated lesions.

The dentin lesions detected on the radiographs with no clinical signs of disease, did not present a different pattern regarding age and gender (Table 2), which is agreement with the findings of Weerheijm, Gruythuysen and Van Amerongen ${ }^{19}$ (1992).

In the patients aged between 10 and 12 years, there was a higher prevalence of enamel-dentin caries (26 teeth), when compared to those aged between 13 and 15 years ( 9 teeth) and between 16 and 18 years (12 teeth), though this was not statistically significant. This result may be due to the fact that in the older teenagers, most of the lesions were cavitated or restored. In those aged between 10 and 12 years, 13 and 15 years and 16 and 18 years, 6,8 and 16 teeth were found to have dentin caries and 9, 17 and 21 teeth were restored, respectively.

When considering the prevalence of enameldentin caries in maxillary and mandibular molars, Weerheijm, Gruythuysen and Van Amerongen ${ }^{19}$ (1992) affirmed that there is no significant difference between maxillary and mandibular arches. Our study found a higher occurrence of enamel-dentin caries in mandibular molars than in maxillary molars, but this difference was not statistically significant (Table 4).

Comparing the presence and distribution of enamel-dentin caries lesions in the various tooth types, the first erupted posterior teeth in the oral cavity had the highest number of enamel-dentin lesions on dentin. The mandibular first molars were affected in 15 of the 47 cases of enameldentin caries, maxillary first molars in 11 cases, second mandibular molars in 13 cases and second maxillary molars in only 4 cases. Of all teeth with enamel-dentin caries detected, only four premolars were affected.

For the second molars, even with the same caries lesion, the clinical condition led to a difficult diagnosis, with criterion 0 (Figure 1) scored incorrectly for more units with enamel-dentin caries (Table 3).

Routine clinical examinations without complementary radiographic examinations do not detect the occurrence of caries lesions in some teeth. In many examinations, radiographic images are carried out only when there is a suspicion of a caries lesion on proximal surfaces ${ }^{9,11}$. This situation is more complex when considering epidemiologic studies involving a larger number of individuals. In these cases, no radiographic images are taken and caries lesions are under-reported ${ }^{3}$.

According to the guidelines of the American Dental Association ${ }^{1}$ (2006), radiographic diagnosis should only be used after clinical examination, considering the dental and general health needs of the patient. Because each patient is different, radiographic examination should be individualized ${ }^{1}$. In the present study, we observed that enameldentin caries could not be detected in clinical examination: $8.41 \%$ of the teeth clinically diagnosed as sound presented dentin caries (Figure 7). Thus, bitewing radiographic images should be considered part of the initial routine dental examination in children. Newman, et al. ${ }^{9}$ (2009) support the recommendations of pediatric dentistry worldwide that bitewing radiography be considered part of the initial routine dental examination of children because the prevalence of hidden occlusal caries detectable only radiographically is approximately $12 \%$.

Civera, et al. ${ }^{5}$ (2007) also concluded that the use of radiographic techniques, conventional or digital, increases the number of caries lesions diagnosed compared to clinical examination alone; 3.23 times more caries lesions were diagnosed using digital images and 2.88 more lesions were diagnosed using conventional radiography, when compared to clinical examination.

Digital radiography is a reality, and its reduced dose of radiation provides real benefits to the patient. Besides having similar accuracy for the detection of caries lesions as conventional radiography $4,6,11,15$, it also has the advantage of not requiring film and chemical processing ${ }^{21}$. More studies on the application of density measurement tools and histograms are necessary.

Early diagnosis of enamel-dentin caries provides the opportunity for non-invasive treatment through remineralization of small lesions, resulting in inactive lesions and preservation of the dental 
structure, function and esthetics ${ }^{12,16}$. Non-invasive treatments were chosen (fluoride therapy and/or sealant placement), by consensual multidisciplinary decision, for 38 of the 47 teeth diagnosed as having enamel-dentin caries.

\section{CONCLUSIONS}

It is important to note that radiographic examination, even using digital systems, presents considerable limitations; for example, one cannot determine if the lesion is active or not, or the presence or absence of cavities. Research on detection of enamel-dentin caries is still ongoing and this study permits the implementation of future studies in this area. It is important to have a precise diagnostic method, with an established protocol for bitewing radiographic images as a reference for all patients that present clinically sound dental units.

\section{ACKNOWLEDGMENTS}

We are grateful to Fapesb (Edital Temático 2004) and CNPq for their contributions for this study.

\section{REFERENCES}

1- American Dental Association Council on Scientific Affairs. The use of dental radiographs: update and recommendations. J Am Dent Assoc. 2006;137:1304-12.

2- Alvarez JO, Navia JM. Nutritional status, tooth eruption, and dental caries: a review. Am J Clin Nutr. 1989;49:417-26.

3- Assaf AV, Meneghim MC, Zanin L, Mialhe FL, Pereira AC, Ambrosano GMB. Assessment of different methods for diagnosing dental caries in epidemiological surveys. Commun Dent Oral Epidemiol. 2004;32:418-25.

4- Castro VM, Katz JO, Hardman PK, Glaros AG, Spencer P. In vitro comparison of conventional film and direct digital imaging in the detection of approximal caries. Dentomaxillofac Radiol. 2007; 36:138-42.

5- Civera VG, Silla JMA, Company JMM, Navarro LF. Clinical and radiographic diagnosis of approximal and occlusal dental caries in a low risk population. Med Oral Patol Oral Cir Bucal. 2007;12:E252-7. 6- Ferreira RI, Haiter-Neto F, Tabchoury CPM, Paiva GAN, Bóscolo FN. Assessment of enamel demineralization using conventional, digital, and digitized radiography. Braz Oral Res. 2006;20:114-9. 7- Lynch RJM, Ten Cate JM. The effects of adjacent dentine blocks on the demineralization and remineralization of enamel in vitro. Caries Res. 2006;40:38-42.

8- Meneghim MC, Assaf AV, Zanin L, Kozlowski FC, Pereira AC, Ambrosano GM. Comparison of diagnostic methods for dental caries. J Dent Child (Chic). 2003;70:115-9.

9- Newman B, Seow WK, Kazoullis S, Ford D, Holcombe T. Clinical detection of caries in the primary dentition with and without bitewing radiography. Aust Dent J. 2009;54:23-30.

10- Parks ET, Williamson GF. Digital radiography: an overview. J Contemp Dent Pract. 2002;3:23-39.

11- Peker I, Toraman Alkurt M, Altunkaynak B. Film tomography compared with film and digital bitewing radiography for proximal caries detection. Dentomaxillofac Radiol. 2007;36:495-9.

12- Pretty IA. Caries detection and diagnosis: novel technologies. J Dent. 2006;34:727-39.
13- Ricketts DNJ, Ekstrand KR, Martignon S, Ellwood R, Alatsaris $M$, Nugent Z. Accuracy and reproducibility of conventional radiographic assessment and subtraction radiography in detecting demineralization in occlusal surfaces. Caries Res. 2007;41:121-8. 14- Souza-Zaroni WC, Ciccone JC, Souza-Gabriel AE, Ramos RP, Corona SAM, Palma-Dibb RG. Validity and reproducibility of different combinations of methods for occlusal caries detection: an in vitro comparison. Caries Res. 2006;40:194-201.

15- Syriopoulos K, Sanderink GCH, Velder XL, Van Der Stelt PF. Radiographic detection of approximal caries: a comparison of dental films and digital imaging systems. Dentomaxillofac Radiol. 2000;29:312-8.

16- Thompson VP, Kaim JM. Nonsurgical treatment of incipient and hidden caries. Dent Clin North Am. 2005;49:905-21.

17- Weerheijm KL. Occlusal "hidden caries". Dent Update. $1997 ; 24: 182-4$.

18- Weerheijm KL, Groen HJ, Bast AJ, Kieft JA, Eijkman MA, Van Amerongen WE. Clinically undetected occlusal dentine caries: a radiographic comparison. Caries Res. 1992;26:305-9.

19- Weerheijm KL, Gruythuysen RJ, Van Amerongen WE. Prevalence of hidden caries. ASDC J Dent Child. 1992;59:408-12. 20- Wenzel A. Bitewing and digital bitewing radiography for detection of caries lesions. J Dent Res. 2004;83:C72-5.

21- Wenzel A. A review of dentists' use of digital radiography and caries diagnosis with digital systems. Dentomaxillofac Radiol. 2006;35:307-14.

22- Wenzel A, Haiter-Neto F, Gotfredsen E. Influence of spatial resolution and bit depth on detection of small caries lesions with digital receptors. Oral Surg Oral Med Oral Pathol Oral Radiol Endod. 2007;103:418-22. 